\title{
Interpregnancy weight gain and childhood obesity: analysis of a UK population-based cohort
}

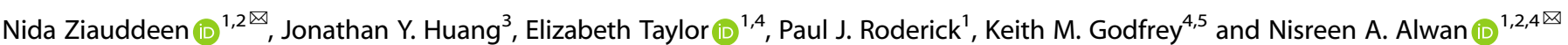

(c) The Author(s) 2021

BACKGROUND: Maternal obesity increases the risk of adverse long-term health outcomes in mother and child including childhood obesity. We aimed to investigate the association between interpregnancy weight gain between first and second pregnancies and risk of overweight and obesity in the second child.

METHODS: We analysed the healthcare records of 4789 women in Hampshire, UK with their first two singleton live births within a population-based anonymised linked cohort of routine antenatal records (August 2004 and August 2014) with birth/early life data for their children. Measured maternal weight and reported height were recorded at the first antenatal appointment of each pregnancy. Measured child height and weight at 4-5 years were converted to age- and sex-adjusted body mass index (BMI z-score). Log-binomial regression was used to examine the association between maternal interpregnancy weight gain and risk of childhood overweight and obesity in the second child. This was analysed first in the whole sample and then stratified by baseline maternal BMI category.

RESULTS: The prevalence of overweight/obesity in the second child was $19.1 \%$ in women who remained weight stable, compared with $28.3 \%$ in women with $\geq 3 \mathrm{~kg} / \mathrm{m}^{2}$ weight gain. Interpregnancy gain of $\geq 3 \mathrm{~kg} / \mathrm{m}^{2}$ was associated with increased risk of childhood overweight/obesity (adjusted relative risk (95\% Cl) $1.17(1.02-1.34)$ ), with attenuation on adjusting for birthweight of the second child (1.08 (0.94-1.24)). In women within the normal weight range at first pregnancy, the risks of childhood obesity ( $\geq 95$ th centile) were increased with gains of $1-3 \mathrm{~kg} / \mathrm{m}^{2}(1.74(1.07-2.83))$ and $\geq 3 \mathrm{~kg} / \mathrm{m}^{2}(1.87(1.18-3.01))$.

CONCLUSION: Children of mothers within the normal weight range in their first pregnancy who started their second pregnancy with a considerably higher weight were more likely to have obesity at 4-5 years. Supporting return to pre-pregnancy weight and limiting weight gain between pregnancies may achieve better long-term maternal and offspring outcomes.

International Journal of Obesity (2022) 46:211-219; https://doi.org/10.1038/s41366-021-00979-z

\section{INTRODUCTION}

The prevalence of obesity in women of reproductive age is rising worldwide and is seen in all populations regardless of income status [1]. Maternal obesity during pregnancy in England has shown a major increase over time, from $7.6 \%$ in 1989 to $15.6 \%$ in 2007 [2] to $22.2 \%$ in 2018/19 [3], with the rate of normal weight pregnancies decreasing from $65.6 \%$ in 2007 to $53.6 \%$ in 2007 [2] and $46.3 \%$ in 2018/19 [3]. Maternal obesity during pregnancy increases the risk of adverse pregnancy outcomes for both mother and child. It also increases the risk of long-term health problems in the child including obesity, cardiovascular disease and diabetes [4].

Pregnancy can alter a woman's weight trajectory due to the risk of weight gain with childbearing for biological and behavioural reasons [5]. Weight gained during pregnancy is not always lost after delivery and thus pregnancy is a risk factor for overweight and obesity in women, which increases with additional pregnancies [6]. Analysis of data from the Danish Medical Birth Registry between 2004 and 2012 showed an increase in maternal BMI with each additional pregnancy [7]. Similarly, childbearing has been found to have a persistent long-term effect on adiposity in women in the UK with a progressive BMI increase observed from nulliparous women to multiparous women with four or more births [8]. A systematic review of 25 studies found that postpartum weight shows a continuous decrease until 12 months following which there is some evidence of increase in weight [5]. Weight retention post-partum is variable with women on average retaining 0.5 to $3 \mathrm{~kg}$; however, a substantial number (12-20\%) retain a considerable amount of weight (up to $17.7 \mathrm{~kg}$ ) [9]. Interpregnancy weight loss in population-based cohorts has ranged from $11 \%$ [10] to $16 \%$ [11].

Birth registration data from England and Wales shows that $63 \%$ of women have two or more children ( $37 \%$ have two, $16 \%$ have three and $10 \%$ have four or more) [12]. An interpregnancy interval

\footnotetext{
${ }^{1}$ School of Primary Care, Population Sciences and Medical Education, Faculty of Medicine, University of Southampton, Southampton, UK. ${ }^{2}$ NIHR Applied Research Collaboration Wessex, Southampton, UK. ${ }^{3}$ Singapore Institute for Clinical Sciences (SICS), Agency for Science, Technology and Research (A*STAR), Singapore, Singapore. ${ }^{4}$ NIHR Southampton Biomedical Research Centre, University of Southampton and University Hospital Southampton NHS Foundation Trust, Southampton, UK. ${ }^{5}$ MRC Lifecourse Epidemiology Unit, University of Southampton, Southampton General Hospital, Southampton, UK. ${ }^{凶}$ email: Nida.Ziauddeen@soton.ac.uk; N.A.Alwan@soton.ac.uk
} 
(interval between the birth of a child to the conception of the next child) of $\geq 36$ months is associated with greater risk of starting a subsequent pregnancy at a higher weight [13]. Previous research has found an increased risk of gestational diabetes (GDM), caesarean section [14-16] and pre-eclampsia [15, 16] with interpregnancy weight gain particularly in women with healthy first pregnancy BMI $\left(<25 \mathrm{~kg} / \mathrm{m}^{2}\right)$. Interpregnancy weight gain is associated with an increased risk of large-for-gestational age (LGA) birth $[10,11,17]$, which, in turn, is associated with both childhood $[18,19]$ and adult obesity [20-22]. The mechanisms are unclear but the increase in adiposity on weight retention or gain postpartum may be a contributing factor to these associations.

Interpreting the findings from studies on maternal weight change is complicated by the fact that weight gain (e.g. amongst underweight) or loss (e.g. amongst overweight) may differ between individuals and across contexts. To address this, our large population-based study primarily focussed on nonunderweight women who maintained or gained weight between their first two pregnancies. The aim was to investigate the association between maternal weight gain between the first and second singleton live birth pregnancies and the risk of overweight and obesity in the second child. As the effect of weight gain/ retention may differ by maternal BMI at the start of the first pregnancy, we stratified the analyses by maternal BMI. To investigate potential mechanisms, we aimed to examine whether birthweight and postnatal factors such as breastfeeding accounted for the observed relationships.

\section{METHODS}

SLOPE (Studying Lifecourse Obesity PrEdictors) is a population-based anonymised linked cohort of prospectively collected routine maternal antenatal and birth records and child health records for all births registered at University Hospital Southampton (UHS), in the South of England, UK between January 2003 and April 2018. UHS is the regional centre for maternity care to residents in the city of Southampton and the surrounding areas of Hampshire. Child healthcare for the same area is provided by two community National Health Service (NHS) trusts; Solent and Southern Health. Thus, the antenatal and birth records $(n=83,481)$ were then linked to child health data from these two community NHS trusts ( $n=74,770,90 \%$ linked).

Records of women with their first two consecutive singleton live birth pregnancies that were successfully linked to child health data for the second child were included. Any woman who had a booking appointment at or after 24 weeks of pregnancy was excluded (Fig. 1). Only pregnancies with feasible gestational age (22-43 weeks), maternal weight and maternal height measurements were eligible for inclusion in this analysis $(n=6357)$. Women who conceived through infertility treatment in either pregnancies $(n=338)$, those who were underweight $\left(\mathrm{BMI}<18.5 \mathrm{~kg} / \mathrm{m}^{2}\right)$ at first $(n=223)$ or second pregnancy $(n=62)$, and those who lost weight $\left(\geq 1 \mathrm{~kg} / \mathrm{m}^{2}\right)$ between pregnancies $(n=945)$ were excluded from this analysis leaving data from $\mathbf{4 7 8 9}$ women for analysis ( $75 \%$ of eligible sample). These exclusions were made to ensure a straightforward comparison between women who maintained and gained weight between pregnancies, and to reduce the potential for residual confounding due to unmeasured changes in health status which may differ between women who lost weight between pregnancies and others.

\section{Exposure assessment}

Maternal weight in kilograms was routinely measured by a midwife at the first antenatal (booking) appointment of each pregnancy [23], which is recommended to take place ideally by 10 weeks gestation in the UK, according to the National Institute for Health and Care Excellence Guidelines [24]. Height was self-reported. BMI was calculated as weight/ (height) ${ }^{2}$.

$\mathrm{BMI}$ at the start of the first pregnancy (baseline BMI) was categorised as normal weight $\left(18.5-24.9 \mathrm{~kg} / \mathrm{m}^{2}\right)$, overweight $\left(25.0-29.9 \mathrm{~kg} / \mathrm{m}^{2}\right)$ and obesity $\left(\geq 30 \mathrm{~kg} / \mathrm{m}^{2}\right)$. Change in BMI was calculated as the difference in BMI measured at the booking appointments of the first two consecutive live birth pregnancies for each woman. After excluding women who lost
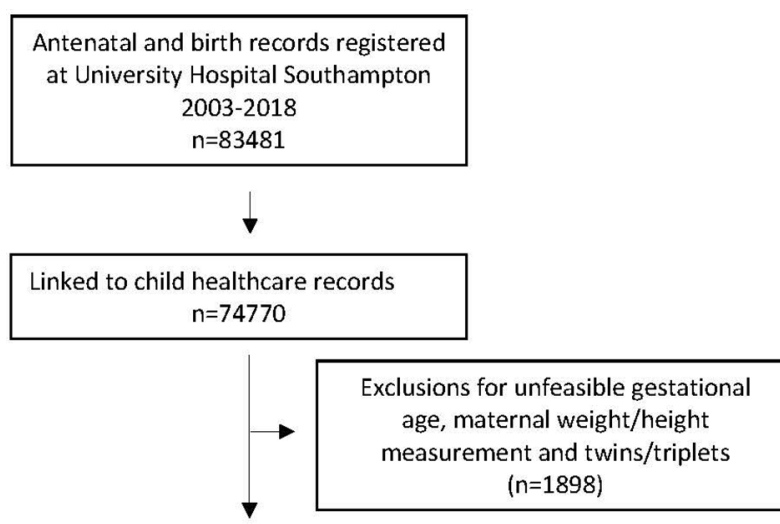

Linked pregnancy and child records $n=72872$

Only one pregnancy in dataset $(n=27281)$

Second or higher order pregnancies only $(n=13271)$

Women with first two consecutive
pregnancies
$n=32320$ records; 16160 women

$\rightarrow \begin{gathered}\text { Late booking }>24 \text { weeks }(n=328) \\ \text { Weight at } 4-5 \text { years in second born child } \\ \text { not available }(n=9474)\end{gathered}$

Women with first two consecutive
live birth pregnancies with second
child's weight measured at $4-5$
years
$n=6357$ women

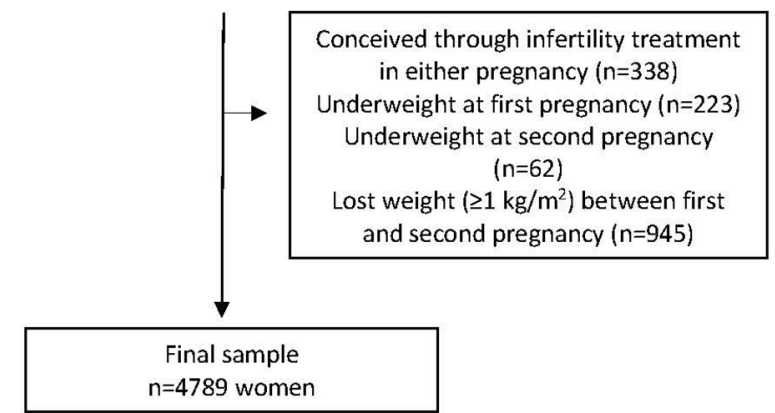

Fig. 1 PRISMA flow diagram. Flowchart of the study including details of inclusion and exclusion criteria.

weight between their pregnancies $\left(\geq 1 \mathrm{~kg} / \mathrm{m}^{2}\right)$, this change was categorised as weight stable $\left(-1\right.$ to $\left.1 \mathrm{~kg} / \mathrm{m}^{2}\right)$, moderate weight gain $\left(1-3 \mathrm{~kg} / \mathrm{m}^{2}\right)$ (MWG) and substantial weight gain $\left(\geq 3 \mathrm{~kg} / \mathrm{m}^{2}\right)$ (SWG).

\section{Outcome assessment}

As part of the National Child Measurement Programme (NCMP), children in all state-maintained schools in England are measured by school nurses at Year R (4-5 years) and Year 6 (10-11 years) [25]. Only the measurement at 4-5 years was used in this analysis and children who did not have a weight and height measurement at $4-5$ years were excluded $(n=9474)$. BMI was then calculated as weight/(height) ${ }^{2}$ and converted to age- and sexadjusted BMI z-scores according to the UK 1990 growth reference charts [26]. The 85th percentile ( $z$-score of +1.04 ) was used to specify the outcome of overweight and obesity and the $95^{\text {th }}$ percentile ( $z$-score of +1.65$)$ was used to specify the outcome of obesity [27, 28]. 


\section{Covariates}

Maternal age (in years) was calculated from date of birth before extraction of the dataset to maintain anonymity. Highest maternal educational qualification was self-reported and categorised as secondary (GCSE) and under, college (A levels) and university degree or above. Self-reported ethnicity was recorded under 16 categories and condensed to White Mixed, Asian, Black/African/Caribbean and Other. Categories of not asked and not stated were coded as missing. Smoking at booking was selfreported as current smoking or non-smoking. Non-smokers were further asked if they had ever smoked or had previously smoked and quit. This was categorised as stopped $>12$ months before conception, stopped $<12$ months before conception or stopped when pregnancy confirmed. Employment status was self-reported and categorised as employed, unemployed, in education, and not specified. In this population, an oral glucose tolerance test was used for screening for GDM in women with one or more risk factors (BMI $>30 \mathrm{~kg} / \mathrm{m}^{2}$ ); GDM in previous pregnancy; previous baby weighing $\geq 4.5 \mathrm{~kg}$; diabetes in parents or siblings and of Asian, African-Caribbean or Middle Eastern ethnicity) [29]. GDM diagnosis was then reported in the database. Interpregnancy interval was defined as the interval between the first live birth and conception of the second pregnancy. The difference in days between two consecutive live births was calculated and gestational age of the latter birth subtracted from this to derive the interpregnancy interval.

Birthweight (grams) was measured by healthcare professionals at birth as part of routine care. Gestational age was based on a dating ultrasound scan which routinely takes place between 10 and 13 weeks gestation [24]. Child sex was recorded at birth.

Breastfeeding status was reported at hospital discharge and during early life. The recording during early life was done differently by the two community NHS Trusts. One used NHS Read codes and thus was recorded at 10 days, 2 weeks, 6 weeks, 4 months and 9 months as breastfed, bottlefed or breast and bottle fed; breastfeeding could be recorded at any or all of the time-points specified by the Read codes. The other Trust recorded breastfeeding at 56 days ( 8 weeks) as yes or no so there was no information on whether this was exclusive or partial breastfeeding. There was a small number $(n<10)$ of responses for breastfeeding for 4 months and 9 months at both pregnancies and no records for 8 weeks (for breastfeeding at first pregnancy only). Using all the information available, a breastfeeding variable was derived with categories of no breastfeeding, minimum 10 days and minimum 6 weeks. Minimum duration was chosen as there was no information how long breastfeeding continued beyond the point of the last record.

\section{Missing data}

Of the women included, $83.9 \%$ of records had missing values for breastfeeding status at first pregnancy, $61.7 \%$ for breastfeeding status at second pregnancy, $3.8 \%$ for ethnicity and $0.3 \%$ on employment status. We imputed 85 datasets using multiple imputation via chained equations. The imputation models included the outcome and variables of analytical interest without missing values to impute the missing values for ethnicity, employment status and breastfeeding status in first and second pregnancy.

\section{Statistical analysis}

Unadjusted comparisons were carried out using ANOVA for continuous variables and chi-square test for categorical variables.

The selection of covariates into the multivariable models were guided by a directed acyclic graph (DAG) (Supplementary Fig. 1) constructed using DAGitty [30]. Covariates comprised maternal age at first pregnancy, ethnicity, highest educational qualification, employment status at first pregnancy, smoking status at first and second pregnancy, first and second pregnancy gestational age at booking, first pregnancy BMI as measured at booking, GDM in first pregnancy, interpregnancy interval and breastfeeding status for first pregnancy (Model 1). To estimate the controlled direct effect of interpregnancy BMI gain, potential mediators were additionally adjusted for including GDM in second pregnancy, birthweight, gestational age at birth and breastfeeding status for second pregnancy (Model 2). Although child sex was included as an adjustment variable in the DAG, this was not included as the outcome is standardized for child sex.

The association between the maternal interpregnancy weight change with risk of childhood overweight and obesity in the second child was examined by fitting generalised linear models predicting each of the two binary outcomes (overweight or obesity) to categories of BMI gain (with stable BMI as the referent category) and covariates using a log link [31] (i.e. log-binomial regression). This was analysed first in the whole sample and then stratified by baseline maternal BMI category. A statistical significance level of 0.05 with $95 \%$ confidence intervals was used in the models.

Covariate adjustments for downstream consequences of exposures (e.g. mediators) has long been known to be a potential source of bias [32], particularly in obstetrics [33] and perinatal epidemiology [34] where adjustments for health indicators such as birthweight and gestational age are common and may lead to paradoxical findings. We investigated the sensitivity of our original models to such collider stratification bias by using inverse probability weighting to balance the distribution of exposure and mediators before any covariate adjustments. Weights were calculated by estimating separate propensity scores for the exposure and each mediator based on their respective confounders specified in the DAG and taking their inverse. Each subject was then weighted by the product of exposure and mediator weights in corresponding analyses. Under the strong assumption that all exposure- and mediator- outcome confounding is properly adjusted with no meaningful interactions, the resulting estimates correspond to the effect of interpregnancy weight change in a population where individuals all have similar likelihood of attaining observed mediator values. That is, if assumptions are fulfilled, such models can be used to estimate of the remaining effect of interpregnancy weight gain on second child overweight if interventions on pregnancy and birth outcomes could be taken.

All analyses were performed using Stata 15 [35].

\section{Ethical considerations}

Data were anonymised by the data holders before being accessed by the research team. Ethics approval was granted by the University of Southampton Faculty of Medicine Ethics Committee (ID 24433) and Health Research Authority (HRA) (IRAS 242031).

\section{RESULTS}

Information on the first and second singleton live birth pregnancies and BMI of second child at 4-5 years was available for 4789 women. Of these, $42.7 \%$ women remained weight stable, $33.5 \%$ exhibited MWG $\left(1-3 \mathrm{~kg} / \mathrm{m}^{2}\right)$ and $23.7 \%$ exhibited SWG $\left(\geq 3 \mathrm{~kg} / \mathrm{m}^{2}\right)$. Mean maternal BMl at second pregnancy was $24.1 \mathrm{~kg} /$ $\mathrm{m}^{2}$ (standard deviation (SD) 4.1) in women who remained weight stable, $26.1 \mathrm{~kg} / \mathrm{m}^{2}$ (SD 4.5) in women with MWG and $31.1 \mathrm{~kg} / \mathrm{m}^{2}$ (SD 5.8) in women with SWG (Table 1). There was a slight increase in the proportion of women with overweight in the second pregnancy but the proportion with obesity nearly tripled from first $(18.3 \%)$ to second $(51.0 \%)$ pregnancy in women with SWG. Thirty percent of women who remained weight stable had overweight or obesity at second pregnancy compared to $50.6 \%$ with MWG and $88.2 \%$ with SWG.

Women with SWG were more likely to be younger, smokers, unemployed and of lower educational attainment and have longer interval between pregnancies compared to those who remained weight stable between pregnancies. Women with SWG were also more likely to have overweight and obesity at both first and second pregnancies.

The prevalence of overweight and obesity at 4-5 years in the second-born child increased from $15.9 \%$ in women who were normal weight at second pregnancy to $33.4 \%$ in women with obesity at the start of second pregnancy (Fig. 2). The prevalence of overweight and obesity in the second-born child increased from $19.1 \%$ in women who remained weight stable between pregnancies to $21.5 \%$ in women with MWG to $28.3 \%$ in women with SWG.

A higher proportion of second-born children of women with SWG had obesity (12.0\%) compared to children of women who remained weight stable (6.9\%) or with MWG (7.5\%). Children of women with SWG were at increased risk of childhood overweight and obesity ( $\geq 95$ th centile) (adjusted relative risk (aRR) 1.17, 95\% confidence interval (Cl) 1.02-1.34) compared to remaining weight stable (Table 2). The relationship was attenuated on adjusting for birthweight, gestational age at birth, gestational diabetes in second pregnancy and breastfeeding status in second pregnancy (aRR $1.08,95 \% \mathrm{Cl} 0.94-1.24$ ). The attenuation was mainly from the 
Table 1. Maternal and birth characteristics categorised by maternal weight change from the first live birth pregnancy for the period of January 2003-September 2017, University Hospital Southampton NHS Foundation Trust, Hampshire, England.

\begin{tabular}{|c|c|c|c|c|}
\hline & $\begin{array}{l}\text { Weight stable ( }>-1 \text { to } \\
<1 \mathrm{~kg} / \mathrm{m}^{2} \text { ) }\end{array}$ & $\begin{array}{l}\text { Moderate weight gain } \\
\left(1-3 \mathrm{~kg} / \mathrm{m}^{2}\right)\end{array}$ & $\begin{array}{l}\text { Substantial weight gain } \\
\left(\geq 3 \mathrm{~kg} / \mathrm{m}^{2}\right)\end{array}$ & $p^{*}$ \\
\hline $\begin{array}{l}\text { Maternal age at first pregnancy, years (mean } \pm \\
\text { SD) }\end{array}$ & $27.1 \pm 5.2$ & $26.2 \pm 5.3$ & $23.7 \pm 5.4$ & $<0.001$ \\
\hline $\begin{array}{l}\text { Maternal age at second pregnancy, years } \\
(\text { mean } \pm \text { SD) }\end{array}$ & $29.8 \pm 5.2$ & $29.1 \pm 5.3$ & $27.0 \pm 5.5$ & $<0.001$ \\
\hline $\begin{array}{l}\text { First pregnancy booking appointment, weeks } \\
\text { (mean } \pm \text { SD) }\end{array}$ & $11.3 \pm 2.5$ & $11.4 \pm 2.6$ & $11.4 \pm 2.8$ & 0.78 \\
\hline $\begin{array}{l}\text { Maternal BMl at first pregnancy booking, } \mathrm{kg} / \mathrm{m}^{2} \\
(\text { mean } \pm \text { SD) }\end{array}$ & $24.0 \pm 4.1$ & $24.3 \pm 4.4$ & $26.0 \pm 5.1$ & $<0.001$ \\
\hline $\begin{array}{l}\text { Maternal BMl at second pregnancy booking, } \\
\mathrm{kg} / \mathrm{m}^{2}(\text { mean } \pm \mathrm{SD})\end{array}$ & $24.1 \pm 4.1$ & $26.1 \pm 4.5$ & $31.1 \pm 5.8$ & $<0.001$ \\
\hline \multicolumn{5}{|l|}{$\begin{array}{l}\text { Maternal BMI category at second pregnancy } \\
\text { booking }(\%, 95 \% \mathrm{Cl})\end{array}$} \\
\hline Normal weight (18.5 to 24.9 ) & 70.0 (67.9 to 71.9$)$ & 49.3 (46.9 to 51.8 ) & $11.8(10.0$ to 13.8$)$ & $<0.001$ \\
\hline Overweight (25.0 to 29.9 ) & 20.7 (19.0 to 22.6$)$ & 33.8 (31.5 to 36.2 ) & $37.2(34.4$ to 40.1$)$ & \\
\hline Obesity $(\geq 30.0)$ & 9.3 (8.1 to 10.6$)$ & 16.8 (15.0 to 18.7$)$ & $51.0(48.1$ to 54.0$)$ & \\
\hline \multicolumn{5}{|l|}{$\begin{array}{l}\text { Maternal smoking status at first pregnancy } \\
\text { booking }(\%, 95 \% \mathrm{Cl})\end{array}$} \\
\hline Never smoked/quit & 55.4 (53.2 to 57.6$)$ & 52.7 (50.2 to 55.2$)$ & 42.0 (39.1 to 44.9$)$ & $<0.001$ \\
\hline Stopped $>1$ year before conceiving & 14.9 (13.3 to 16.5$)$ & 13.5 (11.9 to 15.3$)$ & $9.8(8.1$ to 11.6$)$ & \\
\hline Stopped $<1$ year prior to conceiving & $7.3(6.2$ to 8.5$)$ & 8.9 (7.6 to 10.4$)$ & $8.6(7.1$ to 10.4$)$ & \\
\hline Stopped when pregnancy confirmed & $5.9(4.9$ to 7.0$)$ & 6.9 (5.7 to 8.3$)$ & 10.8 (9.1 to 12.7$)$ & \\
\hline Continued smoking & 10.1 (8.8 to 11.4 ) & 11.7 (10.1 to 13.3$)$ & 21.1 (18.8 to 23.6$)$ & \\
\hline \multicolumn{5}{|l|}{ Maternal education $(\%, 95 \% \mathrm{Cl})$} \\
\hline Secondary (GCSE) or under & 24.4 (22.6 to 26.3$)$ & 28.8 (26.6 to 31.1$)$ & 35.4 (32.7 to 38.3$)$ & $<0.001$ \\
\hline College (A levels) & 40.6 (38.5 to 42.8$)$ & 40.9 (38.5 to 43.4$)$ & 47.9 (45.0 to 50.9 ) & \\
\hline University degree or above & 34.9 (32.9 to 37.0$)$ & 30.3 (28.0 to 32.6$)$ & 16.6 (14.5 to 18.9$)$ & \\
\hline \multicolumn{5}{|l|}{$\begin{array}{l}\text { Maternal employment status at first pregnancy } \\
(\%, 95 \% \mathrm{Cl})\end{array}$} \\
\hline Employed & 89.0 (87.6 to 90.3 ) & 84.6 (82.8 to 86.3 ) & 74.1 (71.5 to 76.7$)$ & $<0.001$ \\
\hline Unemployed & 8.5 (7.4 to 9.8$)$ & 11.5 (9.9 to 13.1$)$ & 19.3 (17.0 to 21.7$)$ & \\
\hline In education & 2.1 (1.5 to 2.8 ) & 3.6 (2.7 to 4.6$)$ & 6.1 (4.8 to 7.6$)$ & \\
\hline Not specified & 0.3 (0.1 to 0.7$)$ & 0.3 (0.1 to 0.8$)$ & $0.5(0.2$ to 1.1$)$ & \\
\hline \multicolumn{5}{|l|}{$\begin{array}{l}\text { Maternal employment status at second } \\
\text { pregnancy }(\%, 95 \% \mathrm{Cl})\end{array}$} \\
\hline Employed & $74.2(72.3$ to 76.1$)$ & 67.7 (65.3 to 69.9$)$ & 55.7 (52.7 to 58.6$)$ & $<0.001$ \\
\hline Unemployed & 24.4 (22.6 to 26.3$)$ & 30.3 ( 28.0 to 32.6$)$ & 42.3 (39.4 to 45.2$)$ & \\
\hline In education & $0.7(0.4$ to 1.2$)$ & $1.2(0.7$ to 1.8$)$ & $1.2(0.7$ to 2.1$)$ & \\
\hline Not specified & $0.6(0.3$ to 1.1$)$ & 0.8 (0.5 to 1.5$)$ & 0.8 (0.4 to 1.5$)$ & \\
\hline
\end{tabular}


Table 1 continued

N

Ethnicity $(\%, 95 \% \mathrm{Cl})$

White
Mixed
Asian

Asian

Black/African/Caribbean

Other

Not specified

Interpregnancy interval (median, IQR)

Interpregnancy interval $(\%, 95 \% \mathrm{Cl})$

0-11 months

$12-23$ months

24-35 months

36 months or more

Birthweight (second pregnancy), grams (mean \pm SD)

Size at birth (second pregnancy)

Small-for-gestational age

Appropriate-for-gestational age

Large-for-gestational age

BMI category at age 4-5 years (second

pregnancy)

Normal weight $(<85$ th centile)

80.9 (79.1 to 82.6$)$

6.1 (5.0 to 7.1 )

80.8 (79.1 to 82.5 )

13.1 (11.7 to 14.7$)$

90.9 (89.6 to 92.1 )

0.6 (0.3 to 1.0$)$

3.1 (2.4 to 4.0 )

0.5 (0.3 to 1.0$)$

0.7 (0.4 to 1.2 )

4.1 (3.3 to 5.1 )

21.4 (14.4 to 31.4 )

16.7 (15.1 to 18.3 )

41.9 (39.7 go 44.0)

24.2 (22.4 to 26.1 )

17.2 (15.6 to 19.0 )

$3505 \pm 501$

12.2 (10.8 to 13.7 )

6.9 (5.9 to 8.1)

Overweight ( $\geq 85$ th- $<95$ th centile)

Obesity ( $\geq 95$ th centile)

\section{Moderate weight gain $\left(1-3 \mathrm{~kg} / \mathrm{m}^{2}\right)$ \\ 1605}

Substantial weight gain
$\left(\geq 3 \mathrm{~kg} / \mathrm{m}^{2}\right)$
1137

87.7 (86.0 to 89.3 )

0.9 (0.5 to 1.5 )

4.5 (3.5 to 5.6 )

1.7 (1.2 to 2.5 )

0.4 (0.2 to 0.9$)$

4.7 (3.7 to 5.8 )

22.7 (13.8 to 33.1 )

87.5 (85.4 to 89.4 )

$<0.001$

1.7 (1.0 to 2.6 )

5.8 (4.5 to 7.3 )

2.5 (1.6 to 3.5 )

0.4 (0.1 to 1.0$)$

2.1 (1.4 to 3.1 )

26.2 (15.6 to 40.5 )

$<0.001$

18.4 (16.6 to 20.4 )

16.7 (14.6 to 19.0$)$

$<0.001$

36.2 (33.8 to 38.6 )

24.6 (22.5 to 26.8 )

20.7 (18.8 to 22.8 )

$3550 \pm 515$

29.4 (26.7 to 32.1 )

23.5 (21.0 to 26.1 )

30.4 (27.8 to 33.2 )

$3560 \pm 547$

0.004

5.3 ( 4.3 to 6.5$)$
80.4 (78.4 to 82.3$)$
$14.3(12.6$ to 16.1$)$

6.5 (5.1 to 8.1)

0.06

76.9 (74.4 to 79.4 )

16.5 (14.4 to 18.8 )

78.5 (76.4 to 80.5 )

71.7 (69.0 to 74.3 )

$<0.001$

${ }^{*} p$ values calculated using ANOVA for continuous and chi-square test for categorical variables.

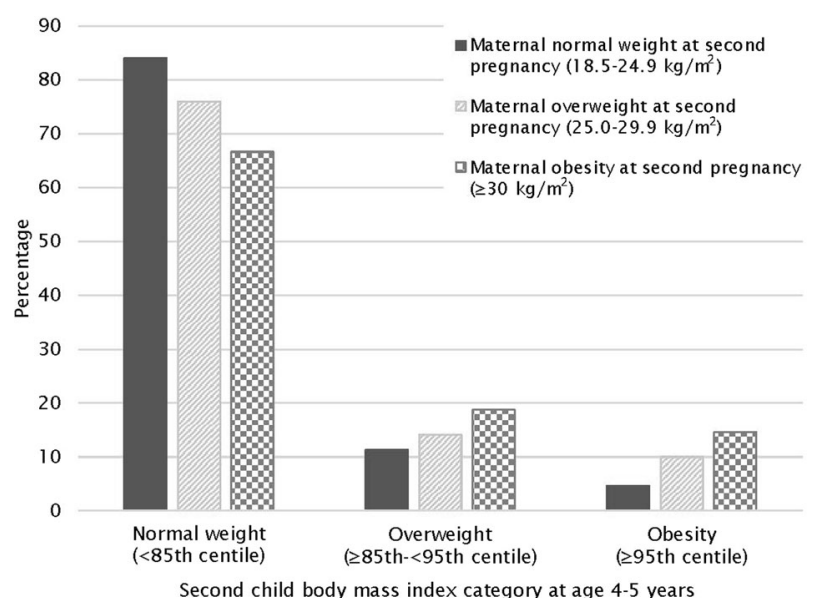

Fig. 2 Prevalence of overweight and obesity in the second child at 4-5 years by maternal BMI category at second pregnancy. Prevalence of overweight and obesity by maternal BMI category.

adjustment for birthweight (Supplementary Table 1). This pattern for SWG was similar in the subgroup with obesity at the start of their first pregnancy (aRR 1.34, 95\% Cl 1.02-1.78, and aRR 1.25, $95 \% \mathrm{Cl} 0.94-1.64$, respectively). A similar pattern was observed in women who were normal weight (aRR $1.16,95 \% \mathrm{Cl} 0.93-1.45$, and aRR $1.07,95 \% \mathrm{Cl} 0.85-1.34)$ at the start of their first pregnancy. There was no evidence of association between MWG weight gain and childhood overweight and obesity. The association between
SWG and childhood overweight and obesity persist when conducted using IPW (Supplementary Table 2).

Both MWG and SWG were associated with increased risk of childhood obesity ( $\geq 95$ th centile) only in women who were normal weight at first pregnancy (aRR $1.55,95 \% \mathrm{Cl} 0.99-2.42$ for MWG and aRR 1.74, 95\% Cl 1.11-2.73 for SWG) (Table 3). The relationship remained on adjusting for mediators of birthweight, gestational age at birth, gestational diabetes in second pregnancy and breastfeeding status in second pregnancy (aRR 1.74, 95\% Cl 1.07-2.83 for MWG and aRR 1.87, 95\% Cl 1.18-3.01 for SWG). There was no evidence of association between interpregnancy weight gain and childhood obesity in women with overweight or obesity at first pregnancy; however, the number of outcome events in this group were quite small. Analysis using IPW found the same association with childhood obesity in women who were normal weight at first pregnancy with SWG (Supplementary Table 3).

Mean weight loss in women who lost weight $\left(\leq-1 \mathrm{~kg} / \mathrm{m}^{2}\right)$ was $2.4 \mathrm{~kg}$ (SD 1.6). In fully adjusted models, the risk of child obesity were lower in mothers who lost weight $\left(\leq-1 \mathrm{~kg} / \mathrm{m}^{2}\right)$ between pregnancies having overweight (aRR $0.69,95 \% \mathrm{Cl} 0.38-1.23$ ) or obesity (aRR $0.92,95 \% \mathrm{Cl} 0.55-1.55$ ) at their first pregnancy. However, the numbers of mothers in these groups were modest (304 and 200 women with overweight and obesitye respectively at first pregnancy) and the confidence intervals wide (Supplementary Table 4).

\section{DISCUSSION}

In this study sample, nearly a quarter of women gained $\geq 3 \mathrm{~kg} / \mathrm{m}^{2}$ between their first and second pregnancies. Children of mothers within the normal weight range and with obesity who started 
their second pregnancy having gained $\geq 3 \mathrm{~kg} / \mathrm{m}^{2}$ from their first pregnancy were more likely to have overweight or obesity ( $\geq 85$ th centile) at the start of primary school; this association was attenuated by accounting for birthweight; likely to be on the causal pathway between interpregnancy BMI gain and offspring obesity. Children of normal weight women who gained weight (1-3 and $\geq 3 \mathrm{~kg} / \mathrm{m}^{2}$ ) from their first pregnancy were more likely to have obesity ( $\geq 95$ th centile) at the start of primary school.

The risk of overweight and obesity in the second child with interpregnancy weight gain was attenuated on adjusting for second pregnancy/birth factors. Maternal overweight and obesity is an established risk factor for GDM, higher birthweight and lower rates of breastfeeding [36], all of which are risk factors for childhood overweight and obesity [37-39]. Weight gain between pregnancies is associated with increased risk of GDM and LGA [14-16], particularly in normal weight women [14, 15]. Previous research examining the association between interpregnancy weight gain and LGA birth showed that women with overweight and obesity who dropped BMI category by their second pregnancy remained at an increased risk but had a lower risk compared to women whose BMl category increased between pregnancies [40]. Offspring of women with overweight and obesity are already at increased risk of childhood obesity and it is possible that the weight change in this subgroup was not large enough to detect a further increase in risk particularly in subgroups with small sample size. Greater efforts on primary prevention of preconception obesity in women of childbearing age are needed. However, it is important that any support policies fully recognise the wider social, environmental, economic and commercial determinants of obesity and avoid any implication of blame on mothers for their children's overweight. Additionally, more effective weight loss measures for women with obesity and support for normal weight women to return to pre-pregnancy weight in the interpregnancy period are needed. Weight loss between pregnancies increases the risk of SGA but reduces the risk of LGA and GDM [14] and may be beneficial in protecting against childhood obesity.

The burden of maternal obesity, a key risk factor for childhood overweight and obesity, is growing and a need to focus on the preconception period has been highlighted to attempt to reverse the cycle and trans-generational effect of maternal obesity. Findings from this study are in line with findings from two previous studies. Analysis of 714 mother-child pairs from a population-based cohort in Australia showed that second-born offspring of women who gained $\geq 4 \mathrm{~kg} / \mathrm{m}^{2}$ between their first and second pregnancy were at higher risk of overweight and obesity than those of women who remained weight stable $(\geq-1$ and $<1 \mathrm{~kg} / \mathrm{m}^{2}$ ) between pregnancies [41]. However, all measurements were self-reported by the mother, the response rate to the survey was low (34\%), the proportion gaining $\geq 4 \mathrm{~kg} / \mathrm{m}^{2}$ was small (38 women) and the analysis only adjusted for maternal factors before the birth of the second child. The proportion of women who remained weight stable in the Australian cohort (44.8\%) was comparable to this cohort $(42.7 \%)$. The other study utilised a population-based linked cohort in Scotland and found that maternal weight gain of $\geq 10 \%$ between pregnancies was associated with increased risk of overweight and obesity in the second-born child compared to remaining weight stable $( \pm 3 \%)$ [42]. However, only $44 \%$ of 59,975 records were successfully linked and 5863 women had more than one pregnancy in the linked dataset.

There is increasing evidence of the importance of the preconception and pregnancy periods on long-term health. A suggested approach to improving preconception health is to promote health of the population more broadly with targeting of women and partners planning a pregnancy [43-45]. It is important to engage with women during the interpregnancy period to optimise their and their children's health and address the barriers 


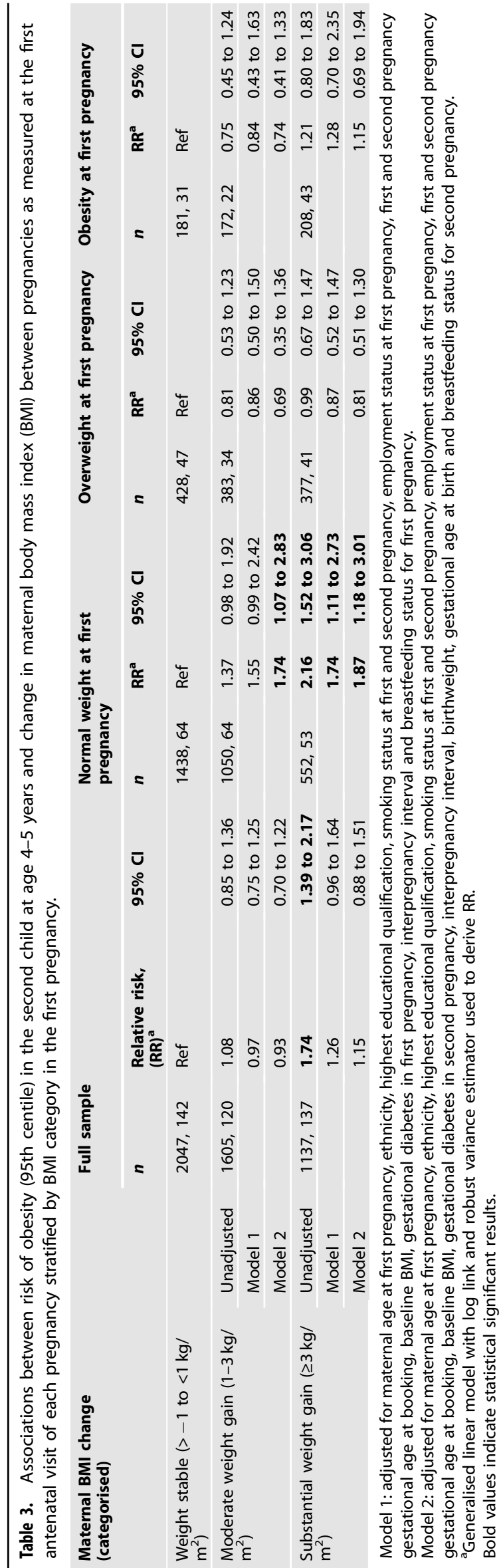

against healthy behaviours as this is also the preconception period for the next pregnancy. The interpregnancy period provides an excellent opportunity to focus on preconception and family health due to the relatively intensive contact with health and care professionals. The feasibility and effectiveness of utilising existing contact time with healthcare professionals during the postpartum period to support maternal health needs to be explored. Mothers may also benefit from mutual support groups. Weight management issues tend to be greater in more disadvantaged mothers so the most effective strategies for such mothers needs to be identified to reduce social inequality in subsequent maternal, birth and child outcomes. As weight gain usually occurs in combination with other risk factors particularly in socioeconomically disadvantaged groups and women at this stage have competing priorities and time demands, a holistic approach taking all this into account should be considered.

\section{Strengths and limitations}

The study sample is from a relatively large population-based cohort including women from all socioeconomic and ethnic backgrounds delivering at a large maternity centre in Southampton, UK, which is representative of the regional population. According to the UK Department of Communities and Local Government English indices of deprivation report, Southampton is more deprived than average, with the situation having worsened between 2010 and 2015 [46]. However, about half of the women included in this analysis reside in the rest of Hampshire (the region where Southampton is situated), which is less deprived. Our sample was $89 \%$ White, which is comparable to the 2011 England and Wales population census of $86 \%$ White [47]. The prevalence of childhood overweight and obesity in this linked sample is comparable to the average for the city of Southampton. The analysis was adjusted for several key confounders that were reasonably complete. Both the maternal weight (used to calculate exposure) and child height and weight (used to define outcome) were objectively measured by healthcare professionals.

An important limitation was the lack of information on gestational weight gain during pregnancy and paternal characteristics/behaviour, which may be mediators in the association between maternal interpregnancy weight gain and childhood overweight and obesity [48]. Breastfeeding initiation and duration after first pregnancy can influence post-partum weight and breastfeeding after the second pregnancy can influence the risk of overweight and obesity in the second child but information on breastfeeding was only recorded in a sixth of first and in little over a third of the second pregnancies so needed to be imputed. Women who had their first booking appointment later into the pregnancy (more than 24 weeks) were excluded from the analysis to ensure comparability of weight measurements between pregnancies. Women who lost weight were also excluded from this analysis to ensure comparability and to reduce the potential for residual confounding. Most of the confounding factors which were accounted for in the analysis were self-reported. Families had to stay in the area to remain under the care of the NHS Trust so data on further pregnancies or outcome data for the child was not available if the family moved outside of the area. Other factors contributing to missing outcome data potentially include changes in recording practices, not attending state school, or the child NHS number (required for linkage) was not recorded with the measurement.

In conclusion, one in five women had a BMl gain $\geq 3 \mathrm{~kg} / \mathrm{m}^{2}$ between their first and second pregnancies. Children of mothers within the normal weight range and with obesity who started their second pregnancy with a considerably higher weight than their first were more likely to have overweight/obesity at the start of primary school; but this could be explained by gestational diabetes and breastfeeding status in the second pregnancy, birthweight and gestational age at birth. Children of normal 
weight women who gained weight between pregnancies were more likely to hav obesity at the start of primary school. The interpregnancy period between two pregnancies is a preconception intervention opportunity for subsequent pregnancies as women and their families have intensive contact with healthcare professionals after birth of a child. There is a need to support return to pre-pregnancy weight in normal weight women and weight loss in women with overweight and obesity.

\section{REFERENCES}

1. Hanson M, Gluckman P, Bustreo F. Obesity and the health of future generations. Lancet Diabetes Endocrinol. 2016;4:966-7.

2. Heslehurst N, Rankin J, Wilkinson JR, Summerbell CD. A nationally representative study of maternal obesity in England, UK: trends in incidence and demographic inequalities in 619323 births, 1989-2007. Int J Obes 2005. 2010;34:420-8.

3. NHS Digital. NHS Maternity Statistics 2018-2019. NHS Digital; 2019 Oct. Available from: https://files.digital.nhs.uk/D0/C26F84/hosp-epis-stat-mat-summaryreport-2018-19.pdf.

4. Poston L. Maternal obesity, gestational weight gain and diet as determinants of offspring long term health. Best Pract Res Clin Endocrinol Metab. 2012;26:627-39.

5. Schmitt NM, Nicholson WK, Schmitt J. The association of pregnancy and the development of obesity - results of a systematic review and meta-analysis on the natural history of postpartum weight retention. Int J Obes. 2007;31:1642-51.

6. Davis EM, Zyzanski SJ, Olson CM, Stange KC, Horwitz RI. Racial, ethnic, and socioeconomic differences in the incidence of obesity related to childbirth. Am J Public Health. 2009;99:294-9.

7. Iversen DS, Kesmodel US, Ovesen PG. Associations between parity and maternal BMI in a population-based cohort study. Acta Obstet Gynecol Scand. 2018;97:694-700.

8. Bobrow KL, Quigley MA, Green J, Reeves GK, Beral V, Million Women Study Collaborators. Persistent effects of women's parity and breastfeeding patterns on their body mass index: results from the Million Women Study. Int J Obes. 2013;37:712-7.

9. Gore SA, Brown DM, West DS. The role of postpartum weight retention in obesity among women: a review of the evidence. Ann Behav Med Publ Soc Behav Med. 2003;26:149-59.

10. Villamor $E$, Cnattingius S. Interpregnancy weight change and risk of adverse pregnancy outcomes: a population-based study. The Lancet. 2006;368:1164-70.

11. Ziauddeen N, Wilding S, Roderick PJ, Macklon NS, Alwan NA. Is maternal weight gain between pregnancies associated with risk of large-for-gestational age birth? Analysis of a UK population-based cohort. BMJ Open. 2019;9:e026220.

12. Office for National Statistics. Childbearing for women born in different years, England and Wales: 2018. 2019 [cited 2020 Aug 25]. Available from: https://www.ons.gov.uk/peoplepopulationandcommunity/ birthsdeathsandmarriages/conceptionandfertilityrates/bulletins/ childbearingforwomenbornindifferentyearsenglandandwales/2017.

13. Ziauddeen N, Roderick PJ, Macklon NS, Alwan NA. The duration of the interpregnancy interval in multiparous women and maternal weight gain between pregnancies: findings from a UK population-based cohort. Sci Rep. 2019;9:9175.

14. Oteng-Ntim E, Mononen S, Sawicki O, Seed PT, Bick D, Poston L. Interpregnancy weight change and adverse pregnancy outcomes: a systematic review and metaanalysis. BMJ Open. 2018;8:e018778.

15. Teulings NEWD, Masconi KL, Ozanne SE, Aiken CE, Wood AM. Effect of interpregnancy weight change on perinatal outcomes: systematic review and metaanalysis. BMC Pregnancy Childbirth. 2019;19:386.

16. Timmermans YEG, Kant KDG, Oosterman EO, Spaanderman MEA, Villamor-Martinez $E$, Kleijnen J, et al. The impact of interpregnancy weight change on perinatal outcomes in women and their children: A systematic review and meta-analysis. Obes Rev. 2020;21: https://doi.org/10.1111/obr.12974.

17. Wallace JM, Bhattacharya S, Campbell DM, Horgan GW. Inter-pregnancy weight change and the risk of recurrent pregnancy complications. PLoS ONE. 2016;11: e0154812.

18. Reilly JJ, Armstrong J, Dorosty AR, Emmett PM, Ness A, Rogers I, et al. Early life risk factors for obesity in childhood: cohort study. BMJ. 2005;330:1357.

19. Danielzik S, Czerwinski-Mast M, Langnäse K, Dilba B, Müller MJ. Parental overweight, socioeconomic status and high birth weight are the major determinants of overweight and obesity in 5-7 y-old children: baseline data of the Kiel Obesity Prevention Study (KOPS). Int J Obes Relat Metab Disord. 2004;28:1494-502.

20. Curhan GC, Willett WC, Rimm EB, Spiegelman D, Ascherio AL, Stampfer MJ. Birth weight and adult hypertension, diabetes mellitus, and obesity in US men. Circulation. 1996;94:3246-50.
21. Curhan GC, Chertow GM, Willett WC, Spiegelman D, Colditz GA, Manson JE, et al. Birth Weight and Adult Hypertension and Obesity in Women. Circulation. 1996;94:1310-5.

22. Phillips D, Young J. Birth weight, climate at birth and the risk of obesity in adult life. Int J Obes. 2000;24:281-7.

23. Inskip H, Crozier S, Baird J, Hammond J, Robinson S, Cooper C, et al. Measured weight in early pregnancy is a valid method for estimating pre-pregnancy weight. J Dev Orig Health Dis. 2020;12:561-69.

24. National Institute of Heath and Care Excellence. Antenatal care for uncomplicated pregnancies. Machester, UK: National Institute of Heath and Care Excellence; 2008 Mar [cited 2020 Aug 25]. Available from: https://www.nice.org.uk/guidance/ cg62.

25. NHS Digital. National Child Measurement Programme. [cited 2020 Aug 25]. Available from: https://digital.nhs.uk/services/national-child-measurementprogramme/.

26. Vidmar S, Carlin J, Hesketh K, Cole T. Standardizing anthropometric measures in children and adolescents with new functions for egen. Stata J Promot Commun Stat Stata. 2004;4:50-5.

27. NHS Digital. National Child Measurement Programme, England 2018/19 School Year [NS]. 2019 Oct [cited 2020 Mar 18]. Available from: https://digital.nhs.uk/ data-and-information/publications/statistical/national-child-measurementprogramme/2018-19-school-year\#.

28. National Obesity Observatory. A simple guide to classifying body mass index in children. 2011.

29. National Institute of Heath and Care Excellence. Diabetes in pregnancy: management from preconception to the postnatal period. 2015 Feb.

30. Textor J, van der Zander B, Gilthorpe MS, Liskiewicz M, Ellison GT. Robust causal inference using directed acyclic graphs: the R package "dagitty.". Int J Epidemiol. 2016;45:1887-94.

31. Cummings P. Methods for estimating adjusted risk ratios. Stata J Promot Commun Stat Stata. 2009;9:175-96.

32. Greenland S. Quantifying biases in causal models: classical confounding vs collider-stratification bias. Epidemiol Camb Mass. 2003;14:300-6.

33. Ananth CV, Schisterman EF. Confounding, causality, and confusion: the role of intermediate variables in interpreting observational studies in obstetrics. Am J Obstet Gynecol. 2017;217:167-75.

34. Whitcomb BW, Schisterman EF, Perkins NJ, Platt RW. Quantification of colliderstratification bias and the birthweight paradox. Paediatr Perinat Epidemiol. 2009;23:394-402.

35. Stata Statistical Software: Release 15. College Station, TX: StataCorp LLC; 2017.

36. Poston L, Caleyachetty R, Cnattingius S, Corvalán C, Uauy R, Herring $S$, et al. Preconceptional and maternal obesity: epidemiology and health consequences. Lancet Diabetes Endocrinol. 2016;4:1025-36.

37. Baptiste-Roberts K, Nicholson WK, Wang N-Y, Brancati FL. Gestational diabetes and subsequent growth patterns of offspring: The National Collaborative Perinatal Project. Matern Child Health J. 2012;16:125-32.

38. Zhu Y, Olsen SF, Mendola P, Yeung EH, Vaag A, Bowers $K$, et al. Growth and obesity through the first $7 \mathrm{y}$ of life in association with levels of maternal glycemia during pregnancy: a prospective cohort study. Am J Clin Nutr. 2016;103: 794-800.

39. Weng SF, Redsell SA, Swift JA, Yang M, Glazebrook CP. Systematic review and meta-analyses of risk factors for childhood overweight identifiable during infancy. Arch Dis Child. 2012;97:1019-26.

40. Getahun D, Ananth CV, Peltier MR, Salihu HM, Scorza WE. Changes in prepregnancy body mass index between the first and second pregnancies and risk of large-for-gestational-age birth. Am J Obstet Gynecol. 2007;196:530.e1-8.

41. Adane AA, Dobson A, Tooth L, Mishra GD. Maternal preconception weight trajectories are associated with offsprings' childhood obesity. Int J Obes. 2018:42:1265-74.

42. Aucott L, Bhattacharya S, McNeill G, Turner S. Differences in body mass index between siblings who are discordant for exposure to antenatal maternal smoking. Paediatr Perinat Epidemiol. 2017;31:402-8.

43. Barker M, Dombrowski SU, Colbourn T, Fall CHD, Kriznik NM, Lawrence WT, et al. Intervention strategies to improve nutrition and health behaviours before conception. The Lancet. 2018;391:1853-64.

44. Stephenson J, Heslehurst N, Hall J, Schoenaker DAJM, Hutchinson J, Cade JE, et al. Before the beginning: nutrition and lifestyle in the preconception period and its importance for future health. The Lancet. 2018;391:1830-41.

45. Stephenson J, Vogel C, Hall J, Hutchinson J, Mann S, Duncan H, et al. Preconception health in England: a proposal for annual reporting with core metrics. The Lancet. 2019;393:2262-71.

46. Department for Communities and Local Government. The English Indices of Deprivation 2015. 2015.

47. Office for National Statistics. Ethnicity and National Identity in England and Wales: 2011. 2012 
48. Nohr EA, Vaeth M, Baker JL, Sørensen TI, Olsen J, Rasmussen KM. Combined associations of prepregnancy body mass index and gestational weight gain with the outcome of pregnancy. Am J Clin Nutr. 2008;87:1750-9.

\section{ACKNOWLEDGEMENTS}

We would like to thank David Cable (Electronic Patient Records Implementation and Service Manager) and Florina Borca (Senior Information Analyst R\&D) at University Hospital Southampton for support in accessing the data used in this study. We thank Solent NHS Trust and Southern Health NHS Foundation Trust for their help in accessing the early life data used in this study.

\section{AUTHOR CONTRIBUTIONS}

Study concept (NZ and NAA), study design (NZ, JYH, EJT and NAA), acquisition and interpretation of the data (NZ and NAA), data cleaning and management (NZ), statistical analysis (NZ), drafting of the manuscript (NZ), revising for content and approval of final version before submission (all authors). NAA is the project's PI.

\section{FUNDING}

This work is supported by an Academy of Medical Sciences and Wellcome Trust Grant [AMS_HOP001\1060 to NAA]. KMG is supported by the UK Medical Research Council (MC_UU_12011/4), the National Institute for Health Research (NIHR Senior Investigator (NF-SI-0515-10042), NIHR Southampton 1000DaysPlus Global Nutrition Research Group (17/63/154) and NIHR Southampton Biomedical Research Centre (IS-BRC-1215-20004)), the European Union (Erasmus+ Programme Early Nutrition eAcademy Southeast Asia573651-EPP-1-2016-1-DE-EPPKA2-CBHE-JP and ImpENSA 598488-EPP-1-2018-1-DEEPPKA2-CBHE-JP), the British Heart Foundation (RG/15/17/3174), the US National Institute On Aging of the National Institutes of Health (Award No. U24AG047867) and the UK ESRC and BBSRC (Award No. ES/M00919X/1). NAA is in receipt of research support from the National Institute for Health Research, NIHR Southampton Biomedical Research Centre and NIHR Applied Research Collaboration Wessex.

\section{COMPETING INTERESTS}

KMG has received reimbursement for speaking at conferences sponsored by companies selling nutritional products, and is part of an academic consortium that has received research funding from Abbott Nutrition, Nestec, BenevolentAl Bio Ltd. and Danone. The other authors have no potential competing interests to declare.

\section{ADDITIONAL INFORMATION}

Supplementary information The online version contains supplementary material available at https://doi.org/10.1038/s41366-021-00979-z.

Correspondence and requests for materials should be addressed to Nida Ziauddeen or Nisreen A. Alwan.

Reprints and permission information is available at http://www.nature.com/ reprints

Publisher's note Springer Nature remains neutral with regard to jurisdictional claims in published maps and institutional affiliations. cc (i) Open Access This article is licensed under a Creative Commons Attribution 4.0 International License, which permits use, sharing, adaptation, distribution and reproduction in any medium or format, as long as you give appropriate credit to the original author(s) and the source, provide a link to the Creative Commons license, and indicate if changes were made. The images or other third party material in this article are included in the article's Creative Commons license, unless indicated otherwise in a credit line to the material. If material is not included in the article's Creative Commons license and your intended use is not permitted by statutory regulation or exceeds the permitted use, you will need to obtain permission directly from the copyright holder. To view a copy of this license, visit http://creativecommons. org/licenses/by/4.0/.

(c) The Author(s) 2021 